\title{
An Empirical Study of Low-income Housing Policy in Small and Medium-sized Areas
}

\author{
SangSu Keum ${ }^{1}$ and HyunWook Ryu ${ }^{2}$ \\ ${ }^{1}$ Dept. of Real Estate, Semyung University, Korea \\ ${ }^{2}$ Dept. of Global Trade and Management, Shinhan University, Korea \\ sskeum@semyung.ac.kr
}

\begin{abstract}
The purpose of this study is to analyze the housing situation of small and medium-sized cities located in the provinces and to provide housing policy data for low-income households by analyzing empirical data concerned low-income households in small and medium-sized cities. 2,252 data for the year 2017 and 2018 of public assistant recipient households are used, and regression analysis of the amount of income recognition was conducted through curve model estimation. Age, the number of household members, and daily workers' income. The estimation of the second and third degrees shows the largest amount of income is recognized when the number of household members reaches six to seven. Due to the low birth rate and increased number of single or two-person households. The results for the full-time and daily working householders show the relationship directly proportional to the dependent variable with statistical significance. The results indicate that it is necessary to promote different approaching policies. The basic direction of the housing welfare policy would have to be more microscopic than the ongoing one. A granular approach is worth the further research.
\end{abstract}

Keywords: Curve estimation, Housing welfare policy, Housing stability, Low-income bracket, Small and medium-sized city

\section{Introduction}

Housing has a greater cost of purchase and maintenance compared to other basic elements, making it difficult for low-income households to stabilize. The situation seems to get worse with the rapid aging of Korean society and the decrease in working age population. While the central and local governments have been implementing various policies for the low-income bracket and/or the socially disadvantaged, but not many are satisfied with the policy as with the number of low-income households gradually increased. The provinces, in a worse position with reduced economic income, face more difficult situation. A more substantial policy direction for supporting low-income people is required to prepare for future demographic changes. In particular, housing welfare for low-income households in small and medium-sized cities located in provincial areas needs analysis with different approach considering regional properties.

Many studies regarding affordable housing policy have been conducted in various countries. [1][2][3] In the United States, topics on low-income housing tax credit have been actively studied as it is the primary form of federal housing support for the low-income bracket. [4][5]

Article history:

Received (March 16, 2019), Review Result (April 12, 2019), Accepted (May 7, 2019) 
Other topics on supplementary housing program include housing allowances, benefits and costs of public housing, and the consequences of housing subsidies to the market. [6][7][8] Studies for the low-income bracket in Korea break into housing conditions and housing program such as housing income. [9][10][11][12]

The purpose of this paper is to provide meaningful information about the housing welfare measures of low-income households in small and medium-sized city, and to deliver proposition for the governments regarding housing welfare policy.

\section{The data}

We use 2,252 property data of public assistance recipient households between 2017 and 2018, and exclude missing values and the data below 50,000 Korean Won from the amount of income recognition in order to raise the degree of confidence. Geographically, the data covers the entire city with its size of small-to-medium in Chungcheong province.

Table 1. Coefficient estimates for age variable

\begin{tabular}{|c|c|c|}
\hline & Variable & Detailed explanation \\
\hline $\begin{array}{l}\text { Residential } \\
\text { Status }\end{array}$ & Residential status & Urban $=1$, Rural $=2$ \\
\hline \multirow{7}{*}{$\begin{array}{l}\text { Household } \\
\text { properties }\end{array}$} & Householder's age & By numbers \\
\hline & Sex & Male $=1$, Female $=2$ \\
\hline & Household members & Number of household members (less than six) \\
\hline & Education & $\begin{array}{c}\text { Elementary graduate }=1 \text {, Middle school graduate }=2 \text {, High school graduate }= \\
3 \text {, College graduate and above }=4, \text { Basicbelow level }=5\end{array}$ \\
\hline & Support obligator & $\mathrm{Y}=1, \mathrm{~N}=2$ \\
\hline & Disability grade & Grade $-1=1$, Grade $2=2$, Grade $-3=3$, Grade $-4=4$, Grade $-5=5$, Grade $-6=6$ \\
\hline & Disability type & $\begin{array}{c}\text { Mental }=1, \text { Physical }=2 \text {, Intellectual }=3, \text { Speech }=4, \text { Visual }=5, \text { Hearing }=6 \text {, } \\
\text { Brain lesions }=7, \text { Epilepsy }=8, \text { Renal }=9, \text { Others }=10\end{array}$ \\
\hline
\end{tabular}




\begin{tabular}{|c|c|c|}
\hline \multirow{5}{*}{$\begin{array}{l}\text { Residential } \\
\text { factors }\end{array}$} & Building condition & $\begin{array}{c}\text { Good }=1, \text { Improvement needed }=2, \text { Repair needed }=3 \text {, Emergency } \\
\text { maintenance needed }=4 \text {, Reconstruction needed }=5 \text {, Others }=6\end{array}$ \\
\hline & Heating type & $\begin{array}{c}\text { Gas }=1 \text {, Oil-burning }=2, \text { Briquet }=3 \text {, Night electricity }=4, \text { Firewood }=5 \text {, } \\
\text { Others }=6\end{array}$ \\
\hline & Housing type & Apartment $=1$, House $=2$, Multi-family house $=3$, Others $=4$ \\
\hline & Housing allowance & $\begin{array}{l}\text { Rent }=1 \text {, Housing stability }=2 \text {, Maintenance }=3 \text {, } \\
\text { Other than housing allowance }=4 \text {, Lending funds }=5\end{array}$ \\
\hline & $\begin{array}{l}\text { Home ownership } \\
\text { scheme }\end{array}$ & $\begin{array}{l}\text { Own }=1 \text {, Public rental }=2 \text {, Public Chonsei }=3 \text {, National rental }=4, \\
\text { The guaranteed(rent })=5 \text {, Chonsei }=6 \text {, Free rental }=7 \text {, Hospital impatient }=8 \\
\text { Private facility }=9, \text { Rent }=10, \text { P. Chonsei }=11 \text {, Loan of use }=12 \text {, Others }=13\end{array}$ \\
\hline $\begin{array}{l}\text { Dependent } \\
\text { variable }\end{array}$ & Income recognition & $\begin{array}{l}\text { Single household (below } \$ 10,760)=1 \text {, 2-person household(below } \$ 1,210,213)=2 \text {, } \\
\text { 3-person household (below } \$ 1,565,593)=3 \text {, 4-person household }(\$ 1,920,973)=4,5 \text { - } \\
\text { person household }(2,276,353)=5 \text {, 6-person household }(\# 2,276,353)=6\end{array}$ \\
\hline
\end{tabular}

The dependent variable is the income recognition for the households subdivided into the following categories; (i) single household below 710,760 KRW, (ii) two-person households below 1,210,213 KRW, (iii) three-person households below 1,565,593 KRW, (iv) four-person households below 1,920,973 KRW, (v) five-person households below 2,276,353 KRW, and (vi) six-person households below 2,276,353 KRW. The independent variables are classified into three groups; (i) location (city center and outskirts), (ii) households characteristics, and (iii) residence factors. Households characteristics are comprised of householder age, householder sex, the number per household, householder's education background, anyone under family responsibility, disability grade, types of disability. Residence factors consist of house condition, heating type, classification homes, housing allowance received, and type of housing. In its descriptive statistics, 'income recognition' has the minimum value of 50,000 KRW and the maximum value of 10,229,161 KRW, and the mean value for the number per household is 1.69.

\section{Curve estimation}

We conduct a nonlinear regression analysis of factors associated with the income recognition.

Table 2. Coefficient estimates for age variable

Independent variable: age
\begin{tabular}{|c|c|c|c|c|c|c|c|c|c|}
\hline \multirow{2}{*}{ equation } & \multicolumn{7}{|c|}{ Model fit } & \multicolumn{5}{c|}{ Curve estimates } \\
\cline { 2 - 10 } & $\mathrm{R}^{2}$ & $\mathrm{~F}$ & $\mathrm{df} 1$ & $\mathrm{df} 2$ & C.I. & constant & $\beta 1$ & $\beta 2$ & $\beta 3$ \\
\hline Linear & .262 & 903.345 & 1 & 2550 & .000 & 70.027 & $-2.488 \mathrm{E}-05$ & & \\
\hline Quadratic & .303 & 552.982 & 2 & 2549 & .000 & 73.485 & $-3.562 \mathrm{E}-05$ & $3.067 \mathrm{E}-12$ & \\
\hline Cubic & .303 & 370.083 & 3 & 2548 & .000 & 74.369 & $-3.942 \mathrm{E}-05$ & $5.385 \mathrm{E}-12$ & $-2.014 \mathrm{E}-19$ \\
\hline
\end{tabular}




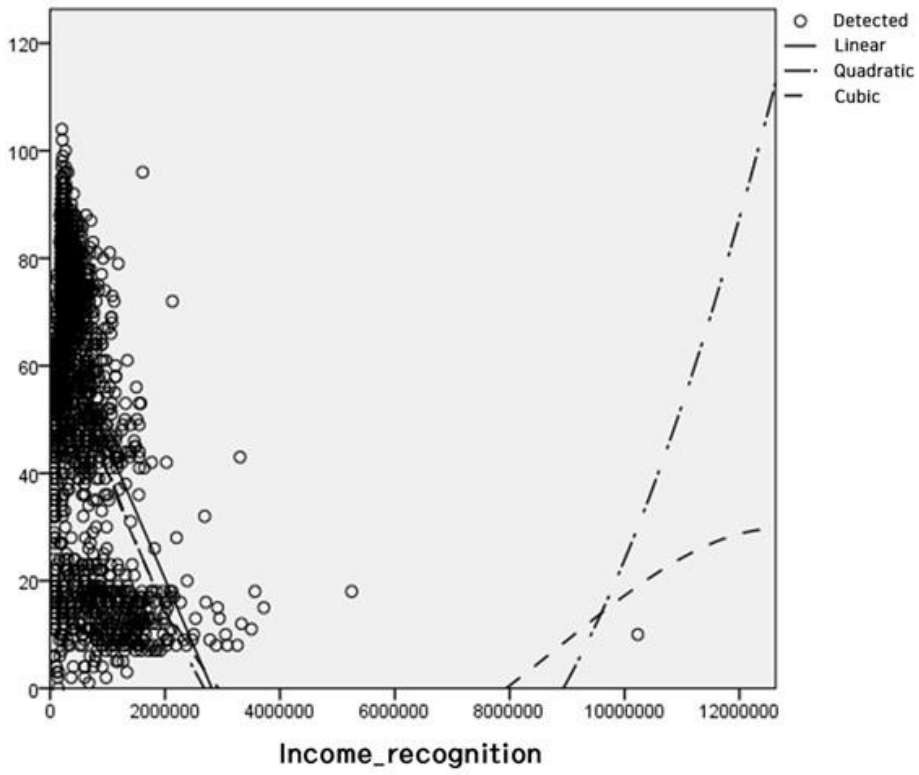

Figure 1. Curve fitting for the householder's age

Curve estimation function of SPSS is used to find the best fit curve for the data. A reliability test is preceded with correlation test. The Pearson correlation coefficient measures a linear relationship among the variables given, and the curve estimation is implemented based upon the coefficients statistically significant at 95 percent confidence interval.

Tested the income recognition associated with age, the nonlinear model is a good fit at all three polynomials from straight line to cubic curve shape. In particular, the two variables are inversely related at the first degree. The table shows that the older the age, the lower the income recognition' received. As the p-value is less than 0.01, the F-test result shows that this model is a good fit. The curve fit is applied and displayed in figure 1. The figure 1 shows the plot after applying the income recognition to the householder's age where linear function is represented in line, quadratic function in dash-dotted, and cubic in dotted line.

Table 3. Coefficient estimates for the number of person per household variable

Independent variable: number of person per household

\begin{tabular}{|c|c|c|c|c|c|c|c|c|c|}
\hline \multirow{2}{*}{ equation } & \multicolumn{4}{|c|}{ Model fit } & \multicolumn{4}{c|}{ Curve estimates } \\
& $\mathrm{R}^{2}$ & $\mathrm{~F}$ & $\mathrm{df1}$ & $\mathrm{df} 2$ & C.I. & constant & $\beta 1$ & $\beta 2$ & $\beta 3$ \\
\hline Linear & .441 & 2012.298 & 1 & 2550 & 0.000 & .998 & $1.546 \mathrm{E}-06$ & & \\
\hline Quadratic & .498 & 1266.278 & 2 & 2549 & 0.000 & .802 & $2.153 \mathrm{E}-06$ & $-1.735 \mathrm{E}-13$ & \\
\hline Cubic & .498 & 844.110 & 3 & 2548 & 0.000 & .790 & $2.206 \mathrm{E}-06$ & $-2.056 \mathrm{E}-13$ & $2.796 \mathrm{E}-21$ \\
\hline
\end{tabular}

The second test for 'income recognition' is conducted for the associated variable of the number per household. All three polynomials are in good fit, and the two variables are directly proportional to each other. The R-squared value for all three equations are close to $50 \%$, thus the variation of dependent variable is well explained. 
The third curve estimation is tested for the associated variable of householder's income. When a householder is full-time worker with constant income, a significant relation is observed for all three curve fitting models. The R-squared values are $0.353,0.405,0.434$ for the equation of linear, quadratic, and cubic respectively, thus the results well explains the proportion of variance in the dependent variable. And the F-values for all three equations indicates the model is in good-fit.

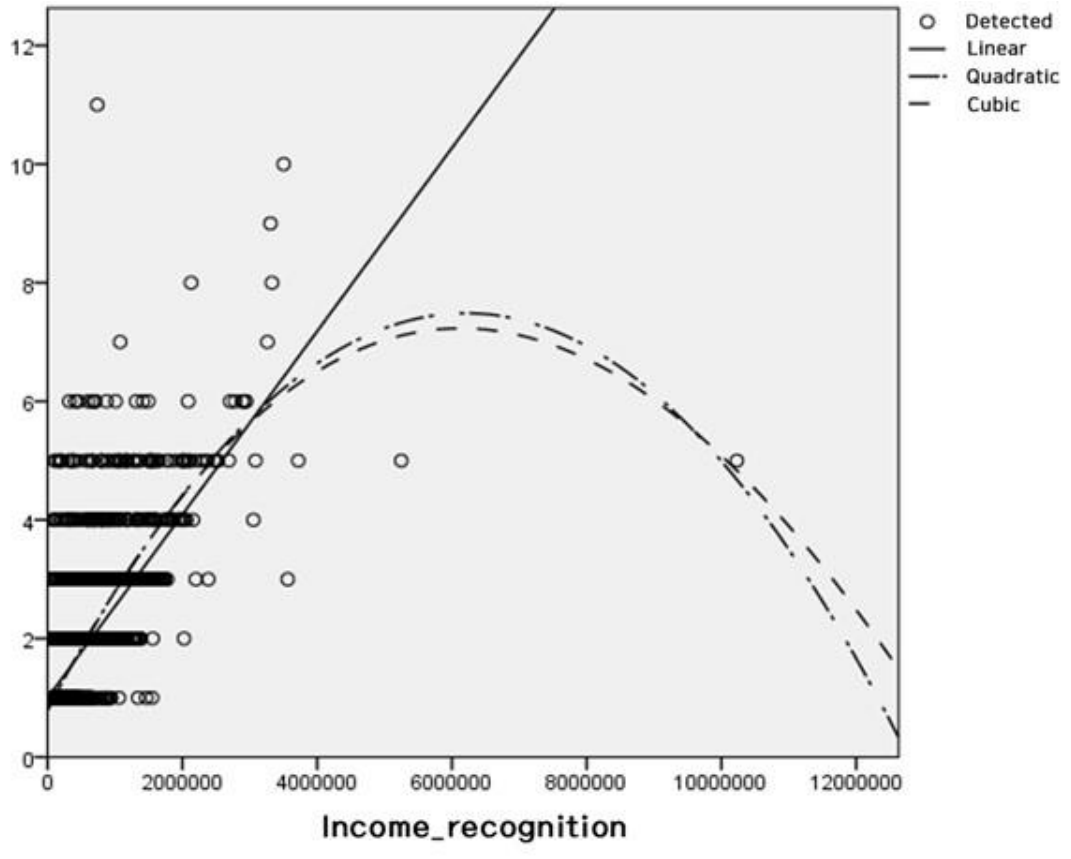

Figure 2. Curve fitting for the number of household members

When a householder is daily worker and applied the householder's income as an independent variable associated to the dependent variable, the model is a good fit at $99 \%$ confidence interval.

Table 4. Coefficient estimates for the income of full-time householder variable

Independent variable: income for full-time householder

\begin{tabular}{|c|c|c|c|c|c|c|c|c|c|}
\hline \multirow{2}{*}{ equation } & \multicolumn{5}{|c|}{ Model fit } & \multicolumn{4}{|c|}{ Curve estimates } \\
\hline & $\mathrm{R}^{2}$ & $\mathrm{~F}$ & df1 & $\mathrm{df} 2$ & C.I. & constant & $\beta 1$ & $\beta 2$ & $\beta 3$ \\
\hline Linear & .353 & 1387.911 & 1 & 2543 & .000 & -98374.782 & .448 & & \\
\hline Quadratic & .405 & 865.540 & 2 & 2542 & .000 & -158752.725 & .636 & $-5.354 \mathrm{E}-08$ & \\
\hline Cubic & .434 & 648.671 & 3 & 2541 & 0.000 & -81512.842 & .304 & $1.491 \mathrm{E}-07$ & $-1.760 \mathrm{E}-14$ \\
\hline
\end{tabular}

In case of other business income, it is proportional to the positive direction to the 'income recognition'. Housing type variable is in inverse relationship with 'income recognition'; therefore, the income is highly recognized when a house privately owned, and recognized lower as the worse the housing type. 


\section{Conclusion}

The estimate for the variables such as the number per household explains that the higher the number of household members, the higher the income recognition. In particular, the estimation of the second and third degrees shows the largest amount of income is recognized when the number of household members reaches six to seven. Due to the low birth rate and increased number of single or two-person households, differentiated policy alternatives are in need. The estimation results of full-time and daily working householders show the relationship directly proportional to the dependent variable with statistical significance. As prior research has provided little evidence on low-income housing policy in medium-sized city, this study presents suggestions based on significant results.

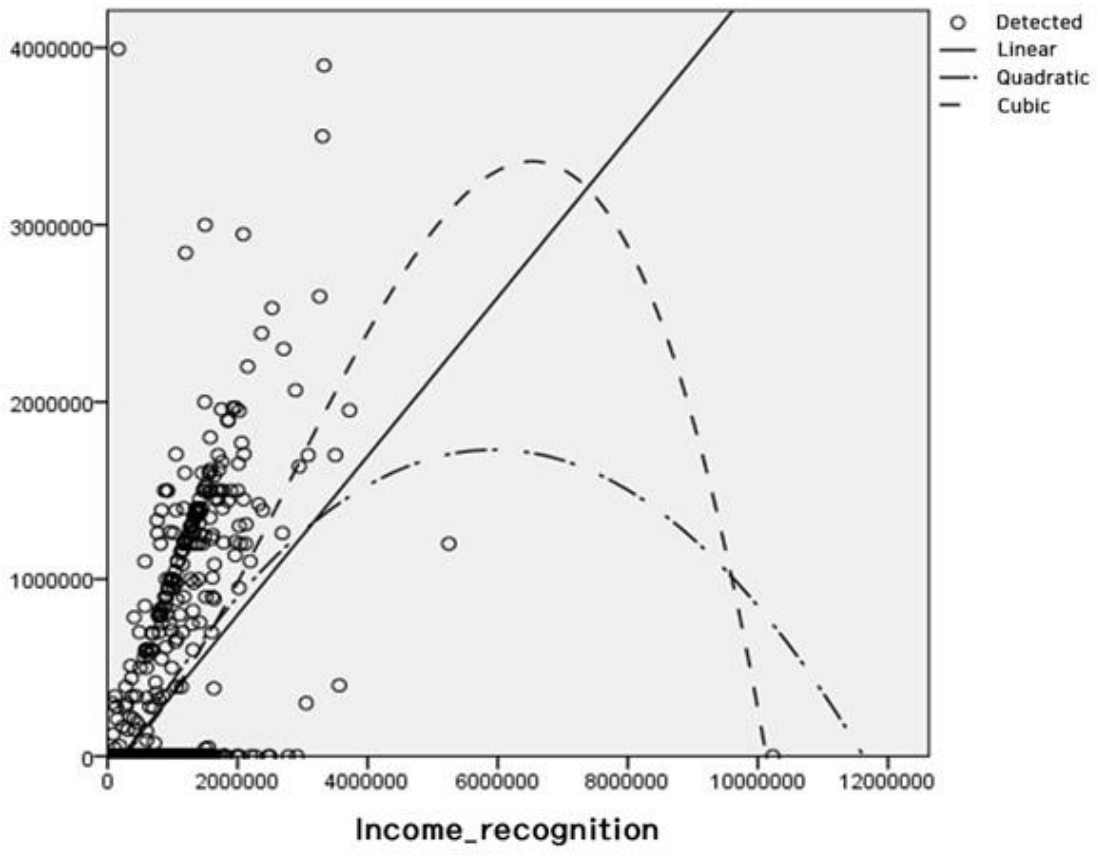

Figure 3. Curve fitting for the income of full-time householders

\section{References}

[1] M. Lekorwe, "The politics of urban governance and management in Gaborone," Pula: Botswana Journal of African Studies, vol.12, pp.69-84, (1998)

[2] D. Le Blanc, and A. Laferrere, "The effects of the existence of public social housing on households' consumption in France," Journal of Housing Economics, vol.10, pp.429-455, (2001) DOI: 10.1006/jhec. 2001.0300

[3] A. M. Mohammad, I. Mansor, and R. R. Yong, "Assessment of residential satisfaction newly designed public low-cost housing in Kuala Lumpur,” Malaysia, Habitat International, vol.34, no.1, pp.18-27, (2010) DOI: 10.1016/j.habitatint.2009.04.002

[4] J. L. Cummings, and D. DiPasquale, "The Low-Income Housing Tax Credit: An Analysis of the First Ten Years," City Research, vol.10, no.2, pp.251-307, (1999) DOI: 10.1080/10511482.1999.9521332

[5] K. McClure, "The low-income housing tax credit as an aid to housing finance: How well has it worked?" Housing Policy Debate, vol.11, no.1, pp.91-114, (2000) DOI: 10.1080/10511482.2000.9521364 
[6] M. P. Murray, "A Potential Hazard of Housing Allowances for Public Housing,” Journal of Urban Economics, vol.4, no.2, pp.119-134, (1977) DOI: 10.1016/0094-1190(77)90018-3

[7] O. O. Edgar and D. M. Barton, "The Benefits and Costs of Public Housing in New York City," Journal of Public Economics, vol.20, no.3, pp.299-332, (1983) DOI: 10.1016/0047-2727(83)90028-2

[8] T. Sinai and J. Waldfogel, "Do low-income housing subsidies increase the occupied housing stock?" Journal of Public Economics, vol.89, no.11-12, pp.2137-2164, (2005) DOI: 10.1016/j.jpubeco.2004.06.015

[9] O. Y. Kim and Y. Moon, "Housing Analysis of One Person Household," Residential Environment, vol.7, no.2, pp.37-53, (2009)

[10] J. Oh and Y. Kim, "A study on the scheme for utilization of private-sector housing for residential stabilization of low-income groups,” Journal of Korea Real Estate Society, vol.29, no.2, pp.35-52, (2011)

[11] M. Y. Jin, "An Assessment of the Revised Housing Benefit Program: Eligibility, Payment and Delivery," Health and Welfare Policy Forum, vol.241, pp.46-63, (2016)

[12] S. Bae and S. Jeon, "Analysis of the spatial distribution and segregation pattern of low-income housing in Seoul,” Planning and Policy, vol.51, pp.191-206, (2006) 
An Empirical Study of Low-income Housing Policy in Small and Medium-sized Areas

This page is empty by intention. 